\title{
Risk factors for prolonged hospitalization and delayed treatment completion after laparoscopic appendectomy in patients with uncomplicated acute appendicitis
}

\author{
Jiyoung Shin, Myong Hoon Ihn, Kyung Sik Kim, Sang Hyun Kim, Jihyoun Lee, Sangchul Yun, \\ Sung Woo Cho \\ Department of Surgery, Soonchunhyang University Seoul Hospital, Soonchunhyang University College of Medicine, Seoul, Korea
}

\begin{abstract}
Purpose: We sought to identify the risk factors for prolonged hospitalization and delayed treatment completion after laparoscopic appendectomy in patients with uncomplicated acute appendicitis.

Methods: The study retrospectively analyzed 497 patients who underwent laparoscopic appendectomies for uncomplicated appendicitis between January 2018 and December 2020. The patients were divided into an early discharge group ( $\leq 2$ days) and a late discharge group ( $>2$ days) based on the length of hospital stay (LOS). The patients were also divided into uneventful and complicated groups according to the need for additional treatment after standard follow-up. Results: Thirty-seven patients (7.4\%) were included in the late discharge group. The mean LOS of the late discharge groups was 3.9 days. There were significant differences according to age, preoperative C-reactive protein (CRP), and operative time between the 2 groups. Only operative time was significantly associated with prolonged LOS in multivariate analysis. Thirty-five patients (7.0\%) were included in the complicated group. The mean duration of treatment in the uneventful and complicated groups was 7.4 and 25.3 days, respectively. Significant differences existed between the uneventful and complicated groups in preoperative body temperature, preoperative CRP levels, maximal appendix diameter, and the presence of appendicoliths. In multivariate analysis, preoperative CRP levels and maximal appendix diameter were independent predictors of delayed treatment completion.

Conclusion: Shorter operative time is desirable to ensure minimal hospital stay in patients with uncomplicated appendicitis. Further efforts are needed to ensure that patients with uncomplicated appendicitis do not experience delayed treatment completion after laparoscopic appendectomies.
\end{abstract}

Keywords: Laparoscopy; Appendectomy; Appendicitis; Length of stay; Postoperative complications

\section{INTRODUCTION}

Acute appendicitis is one of the most common causes of acute abdominal pain requiring emergency surgery, with an estimated

Received: Aug 26, 2021 - Revised: Sep 30, 2021 • Accepted: Oct 12, 2021 Correspondence to: Myong Hoon Ihn, MD

Department of Surgery, Soonchunhyang University Seoul Hospital, Soonchunhyang University College of Medicine, 59 Daesagwan-ro, Yongsan-gu, Seoul 04401, Korea

Email:88082@schmc.ac.kr

ORCID: https://orcid.org/0000-0002-9522-401X

(C) 2023 The Korean Society of Coloproctology

This is an open-access article distributed under the terms of the Creative Commons Attribution NonCommercial License (https://creativecommons.org/licenses/by-nc/4.0) which permits unrestricted noncommercial use, distribution, and reproduction in any medium, provided the original work is properly cited. lifetime risk of $7 \%$ to $8 \%$ worldwide [1]. Despite advances in antibiotic management, appendectomy is generally regarded as the treatment of choice for acute appendicitis [2]. In addition, laparoscopic appendectomy has been the gold standard treatment for acute appendicitis, especially in high-income countries [3], because of advantages such as shorter length of hospital stay (LOS), less postoperative pain, earlier postoperative recovery, lower complication rate, and better cosmetic results compared to conventional open appendectomy [4-6].

Efforts to reduce LOS after laparoscopic appendectomy may relieve pressure on hospital bed capacity, decrease healthcare costs, and improve treatment satisfaction. Many studies have evaluated the safety and feasibility of early discharge after laparoscopic appendectomy [7]. However, as with any surgical procedure, ap- 
proximately $2 \%$ to $23 \%$ of laparoscopic appendectomy patients experience postoperative complications $[8,9]$. In addition, several studies have reported that $3 \%$ of the patients who underwent appendectomy with or without laparoscopy were readmitted for postoperative complications $[10,11]$. Although these unfavorable postoperative outcomes are rare in appendectomies compared to other abdominal surgeries, prolonged hospitalization and delayed completion of treatment can lead to an eventual increase in overall healthcare costs.

Several factors including age, preoperative white blood cell (WBC) counts, preoperative C-reactive protein (CRP) levels, the severity of inflammation including peritonitis or abscess, and open conversion have been associated with prolonged LOS in patients following laparoscopic appendectomy [12-14]. However, these studies included complicated appendicitis, which is clearly distinguished from uncomplicated appendicitis. In addition, few studies have assessed factors that delay treatment completion after laparoscopic appendectomy in patients with uncomplicated appendicitis.

Therefore, we sought to identify the risk factors for prolonged LOS and delayed treatment completion after laparoscopic appendectomies in patients with uncomplicated acute appendicitis.

\section{METHODS}

This study was performed in accordance with the Declaration of Helsinki and approved by the Institutional Review Board at the Soonchunhyang University Seoul Hospital (No. 2021-08-022). Informed consent was waived according to the institutional rules for retrospective studies.

Patients treated with laparoscopic appendectomies for acute appendicitis at the Soonchunhyang University Seoul Hospital between January 2018 and December 2020, were retrospectively analyzed. The study included patients with uncomplicated appendicitis, defined as an acutely inflamed appendix with no evidence of perforation, periappendiceal abscess, or generalized peritonitis based on abdominal computed tomography (CT) or operative findings. Patients were excluded if they were diagnosed with complicated appendicitis, underwent conventional open surgery, or had evidence of malignancy.

All patients were admitted through an emergency room, and abdominal CT scan or ultrasonography (USG) were performed for diagnosis. Magnetic resonance imaging (MRI) was considered as the second-line modality for suspected acute appendicitis in pregnancy patients. All operations were performed laparoscopically by 6 surgeons with at least 5 years of surgical experience. All patients received preoperative treatment with 2 nd generation cephalosporin and were administered antibiotics until 24 hours after surgery. Oral feeding with clear liquids was resumed when the patients were fully awakened after surgery. Patients were discharged when a regular diet was tolerated, ambulation was achieved, and the pain was adequately controlled with oral anal- gesics. Patients were usually followed up at 7 days postoperatively. However, all patients were not followed up regularly, because of the physicians' outpatient schedules or patients' preferences. Therefore, a delayed outpatient visit that does not require any additional treatment due to physicians' outpatient schedules or patient' preference was considered a standard follow-up.

The patients were divided into 2 groups according to the postoperative LOS as described in a previous study [15]. The early discharge group was defined by a LOS of within 2 postoperative days, and the late discharge group was defined by a LOS exceeding 3 postoperative days. In addition, we divided the patients into 2 groups according to the time required for treatment completion. The uneventful group was comprised of patients who did not require additional treatment or follow-up after suture material removal in the standard follow-up and the complicated group was comprised of patients who did require additional treatment or follow-up including readmission after standard follow-up.

The parameters recorded included age, sex, body mass index, hypertension, diabetes mellitus, American Society of Anesthesiologists physical status classification, smoking history, previous surgical history, preoperative body temperature, preoperative WBC count, preoperative CRP level, maximal appendix diameter, the presence of appendicoliths, the time from admission to surgery, surgeon, operative time and operative time of each surgeon, LOS, postoperative morbidity and mortality within 30 days following surgery, reoperation, and readmission.

Operative mortality was defined as death within 30 days of surgery. Postoperative complications were evaluated using the Clavien-Dindo classification (CDC) [16]. Surgical site infections (SSI) were classified into superficial incisional SSIs and deep incisional or organ/space SSIs [17]. Intraabdominal complications, including abscess or stump leakage, were detected by abdominal CT scan.

Categorical variables were analyzed using the chi-square test or Fisher exact test. Continuous variables were compared using Student t-tests. Variables with $\mathrm{P}$-values of $<0.1$ in univariate analyses were included in multivariate logistic regression to identify factors that were independently and significantly associated with prolonged LOS and delayed treatment completion. P-values of $<0.05$ were considered statistically significant. Statistical analyses were performed using IBM SPSS ver. 26.0 (IBM Corp).

\section{RESULTS}

Between January 2018 and December 2020, 632 patients underwent laparoscopic appendectomies for acute appendicitis at a single institution. Of these, 497 patients were included in the study. A total of 135 patients were excluded because of complicated appendicitis in 133 patients, and appendiceal malignancies in 2 patients. Of the entire patients included, 496 patients underwent abdominal CT scan, including 2 children with an ambiguous diagnosis of acute appendicitis on USG and 3 patients with impaired 
renal function who underwent noncontrast-enhanced CT scan. One pregnant patient underwent abdominal MRI because of an ambiguous diagnosis of acute appendicitis on USG.

The mean age of the study subjects was $42.3 \pm 15.7$ years and the study included 254 male patients (51.1\%). The overall mean LOS was $2.1 \pm 0.7$ days. A total of 37 patients (7.4\%) were included in the late discharge group. The mean LOS of the early and late discharge groups was $1.9 \pm 0.3$ days (range, $0-2$ days) and $3.9 \pm 1.7$ days (range, 3-10 days), respectively $(\mathrm{P}<0.001)$. There were no significant differences in baseline characteristics between the 2 groups, except for age and operative time. The mean ages of the 2 groups were $41.9 \pm 15.5$ and $47.4 \pm 17.3$ years, respectively $(\mathrm{P}=$ $0.041)$. The mean operative times of both groups were $39.3 \pm 17.5$ and $47.2 \pm 19.3$ minutes, respectively $(\mathrm{P}=0.009)$. A total of 3 surgeons showed a significant difference in operative time between 2 groups. No patients were converted to conventional open surgery (Table 1).

Postoperative outcomes and the reasons for prolonged LOS are summarized in Table 2. Overall postoperative complications occurred in 85 patients (17.1\%), including 64 (75.3\%) CDC grade 1 and 21 (24.7\%) CDC grade 2 complications. Significant differences were found in overall complications between the early and late discharge groups $(\mathrm{P}<0.001)$. SSI and readmission were not significantly different between the 2 groups after laparoscopic appendectomy. No patient reoperation or mortality occurred within 30 days after surgery. The most common factors underlying prolonged LOS were postoperative ileus (27.0\%) and pain (27.0\%). Wound complications were detected in 2 patients (5.4\%) during in-hospital stays. Three patients refused to be discharged for personal reasons without any complications after surgery (Table 2).

Table 3 shows the results of multivariate logistic regression analysis of the risk factors for prolonged LOS. We found significant differences in prolonged LOS according to age, preoperative CRP levels, and operative time in univariate analysis. In multivariate analysis, only operative time (odds ratio [OR], 1.021; 95\% confidence interval $[\mathrm{CI}], 1.005-1.038 ; \mathrm{P}=0.011)$ was an independent predictor of prolonged LOS.

Of 497 consecutive patients, 35 patients (7.0\%) were included in the complicated group. The overall mean duration of treatment was $8.6 \pm 5.2$ days (range, $6-48$ days). The mean duration of treatment in the uneventful and complicated groups was $7.4 \pm 0.8$ and $25.3 \pm 8.9$ days, respectively $(\mathrm{P}<0.001)$. Significant differences existed between the uneventful and complicated groups according to preoperative body temperature, preoperative CRP levels, maximal appendix diameter, and the presence of appendicoliths. No patient was lost to follow-up until treatment completion (Table 4).

Postoperative complications including SSI and readmission differed significantly between the uneventful and complicated groups. The frequency of $\mathrm{CDC}$ grade 1 complications was higher in the uneventful group, whereas the frequency of CDC grade 2 was higher in the complicated group. A total of 5 patients (1.0\%) were readmitted because of an intraabdominal abscess in 3 pa- tients and postoperative ileus in 2 patients, and all patients were treated conservatively without surgical intervention. Delayed treatment completion was attributed to SSI in all patients, such as wound infections in 21 patients (60.0\%), wound seroma in 9 patients (25.7\%), intraabdominal abscess in 3 patients (8.6\%), wound cellulitis in 1 patient (2.9\%), and skin dehiscence in $1 \mathrm{pa}-$ tient (2.9\%). Only 1 patient who manifested a wound seroma during hospitalization was treated until completion within the standard follow-up period (Table 5).

Table 6 presents the results of multivariate logistic regression analysis of risk factors for delayed treatment completion. We found significant differences in delayed treatment completion according to the preoperative body temperature, preoperative CRP levels, maximal appendix diameter, the presence of appendicolith, and operative time in univariate analysis. In multivariate analysis, preoperative CRP levels (OR, 1.384; 95\% CI, 1.121-1.568; $\mathrm{P}=0.007)$ and maximal appendix diameter (OR, 1.424; $95 \% \mathrm{CI}$, 1.233-1.645; $\mathrm{P}<0.001)$ were independent predictors of delayed treatment completion.

\section{DISCUSSION}

This study demonstrated the role of risk factors in prolonging LOS after laparoscopic appendectomies in patients with uncomplicated appendicitis. To the best of our knowledge, this was the first study to evaluate the factors that delayed treatment completion after a laparoscopic appendectomy in patients diagnosed with uncomplicated appendicitis. Our results revealed that operative time was an independent risk factor for prolonged hospitalization. In addition, preoperative CRP levels and maximal appendix diameter strongly delayed treatment completion after laparoscopic appendectomy.

The LOS after a laparoscopic appendectomy varies by country, surgeon' preference, and culture. Recently, the mean LOS after a laparoscopic appendectomy for uncomplicated appendicitis ranged from 1.6 to 4.2 days in Korea $[15,18]$ and from 0 to 3 days in other countries $[19,20]$. The relatively longer hospital stays in Korea probably reflect a generous national public medical insurance system. In the present study, the overall mean LOS was $2.1 \pm 0.7$ days, which was included within the LOS ranges previously reported in both Korea and other countries. Therefore, our results are reliable.

Some studies reported that operative time was associated with prolonged LOS after laparoscopic appendectomy $[12,13,15]$, although the mechanism is unclear. It is well known that difficult cases require extended duration of treatment, including pneumoperitoneum, irrigation, and other surgical maneuvers, which may contribute to contamination of the abdominal cavity [21]. We observed that longer operative times were related to prolonged LOS. In the present study, 3 of 6 surgeons showed a significant difference in operative time between early and late discharge groups, which was not expected to be biased by the weighted surgeons. In 
Table 1. Characteristics of patients in the early and late discharge groups

\begin{tabular}{|c|c|c|c|}
\hline Characteristic & Early discharge group & Late discharge group & P-value \\
\hline No. of patients & 460 & 37 & \\
\hline Length of hospital stay (day) & $1.9 \pm 0.3(0-2)$ & $3.9 \pm 1.7(3-10)$ & $<0.001$ \\
\hline Age (yr) & $41.9 \pm 15.5$ & $47.3 \pm 17.3$ & 0.041 \\
\hline Sex & & & 0.123 \\
\hline Male & $240(52.2)$ & $14(37.8)$ & \\
\hline Female & $220(47.8)$ & $23(62.2)$ & \\
\hline Body mass index $\left(\mathrm{kg} / \mathrm{m}^{2}\right)$ & $23.5 \pm 3.8$ & $22.9 \pm 3.4$ & 0.347 \\
\hline Hypertension & & & 0.606 \\
\hline No & $400(87.0)$ & $34(91.9)$ & \\
\hline Yes & $60(13.0)$ & $3(8.1)$ & \\
\hline Diabetes mellitus & & & 0.200 \\
\hline No & $442(96.1)$ & $34(91.9)$ & \\
\hline Yes & $18(3.9)$ & $3(8.1)$ & \\
\hline ASA PS classification & & & 0.214 \\
\hline । & $255(55.4)$ & $21(56.8)$ & \\
\hline । & $198(43.0)$ & $14(37.8)$ & \\
\hline$\geq I I I$ & $7(1.5)$ & $2(5.4)$ & \\
\hline Smoking history & & & $>0.999$ \\
\hline No & $364(79.1)$ & $30(81.1)$ & \\
\hline Yes & $96(20.9)$ & $7(18.9)$ & \\
\hline Previous surgical history & & & $>0.999$ \\
\hline No & 409 (88.9) & 33 (89.2) & \\
\hline Yes & $51(11.1)$ & $4(10.8)$ & \\
\hline Preoperative body temperature $\left({ }^{\circ} \mathrm{C}\right)$ & $37.4 \pm 0.6$ & $37.5 \pm 0.9$ & 0.282 \\
\hline Preoperative WBC count $\left(\times 10^{9} / \mathrm{L}\right)$ & $11.9 \pm 4.0$ & $11.3 \pm 4.1$ & 0.424 \\
\hline Preoperative CRP level (mg/L) & $1.7 \pm 2.9$ & $2.6 \pm 3.8$ & 0.075 \\
\hline Maximal appendix diameter (mm) & $10.3 \pm 2.4$ & $10.5 \pm 2.7$ & 0.548 \\
\hline Appendicolith & & & 0.350 \\
\hline No & $322(70.0)$ & $29(78.4)$ & \\
\hline Yes & $138(30.0)$ & $8(21.6)$ & \\
\hline Time from admission to surgery (min) & $444.2 \pm 272.6$ & $414.3 \pm 274.5$ & 0.521 \\
\hline Surgeon & & & 0.151 \\
\hline A & 89 (19.3) & $12(32.4)$ & \\
\hline B & $99(21.5)$ & $4(10.8)$ & \\
\hline C & $85(18.5)$ & $10(27.0)$ & \\
\hline $\mathrm{D}$ & $65(14.1)$ & $2(5.4)$ & \\
\hline $\mathrm{E}$ & $82(17.8)$ & $6(16.2)$ & \\
\hline $\mathrm{F}$ & $40(8.7)$ & $3(8.1)$ & \\
\hline Operative time (min) & $39.3 \pm 17.5$ & $47.2 \pm 19.3$ & 0.009 \\
\hline Surgeon $\mathrm{A}$ & $45.3 \pm 22.9$ & $58.1 \pm 17.6$ & 0.048 \\
\hline Surgeon B & $32.5 \pm 12.0$ & $27.3 \pm 3.7$ & 0.232 \\
\hline Surgeon $\mathrm{C}$ & $46.6 \pm 18.4$ & $41.1 \pm 13.5$ & 0.364 \\
\hline Surgeon D & $31.3 \pm 12.6$ & $27.0 \pm 2.8$ & 0.636 \\
\hline Surgeon $\mathrm{E}$ & $39.9 \pm 15.5$ & $56.2 \pm 21.3$ & 0.018 \\
\hline Surgeon F & $38.5 \pm 12.5$ & $57.0 \pm 24.4$ & 0.026 \\
\hline
\end{tabular}

Values are presented as mean \pm standard deviation (range) or number (\%).

ASA, American Society of Anesthesiologists; PS, physical status; WBC, white blood cell; CRP, C-reactive protein. 
Table 2. Details of postoperative outcomes and factors underlying prolonged hospital stay

\begin{tabular}{|c|c|c|c|}
\hline Characteristic & Early discharge group $(n=460)$ & Late discharge group $(n=37)$ & P-value \\
\hline Clavien-Dindo classification & & & $<0.001$ \\
\hline 0 & 409 (88.9) & $3(8.1)$ & \\
\hline I & $36(7.8)$ & $28(75.7)$ & \\
\hline$\|$ & $15(3.3)$ & $6(16.2)$ & \\
\hline Surgical site infection & & & 0.147 \\
\hline No & $428(93.0)$ & 33 (89.2) & \\
\hline Superficial & $17(3.7)$ & $4(10.8)$ & \\
\hline Deep incisional & $12(2.6)$ & $0(0)$ & \\
\hline Organ/space & $3(0.7)$ & $0(0)$ & \\
\hline Readmission & & & $>0.999$ \\
\hline No & $455(98.9)$ & $37(100.0)$ & \\
\hline Yes & $5(1.1)$ & $0(0)$ & \\
\hline Reoperation & $0(0)$ & $0(0)$ & \\
\hline 30-day mortality & $0(0)$ & $0(0)$ & \\
\hline Reasons for prolonged hospital stay (case) & & $39(100)$ & \\
\hline Postoperative ileus & & $10(25.6)$ & \\
\hline Postoperative pain & & $10(25.6)$ & \\
\hline Enterocolitis & & $4(10.2)$ & \\
\hline Respiratory complication & & $3(7.7)$ & \\
\hline Wound complication & & $2(5.1)$ & \\
\hline Poor oral intake & & $2(5.1)$ & \\
\hline Urinary dysfunction & & $2(5.1)$ & \\
\hline Arrhythmia & & $1(2.6)$ & \\
\hline Dysmenorrhea & & $1(2.6)$ & \\
\hline Jaundice & & $1(2.6)$ & \\
\hline Patient refusal & & $3(7.7)$ & \\
\hline
\end{tabular}

Values are expressed as number (\%).

Table 3. Multivariate analysis of factors affecting prolonged hospital stay

\begin{tabular}{lcc}
\hline Characteristic & OR $(95 \% \mathrm{Cl})$ & P-value \\
\hline Age & $1.020(0.998-1.041)$ & 0.073 \\
Preoperative C-reactive protein & $1.053(0.963-1.151)$ & 0.257 \\
Operative time & $1.021(1.005-1.038)$ & 0.011 \\
\hline
\end{tabular}

addition, although there might be differences in operative time of each surgeon for laparoscopic appendectomy, the surgeons involved in this study had at least 5 years of surgical experience. Therefore, we thought that increased operative time including extensive manipulation of the appendix might be attributed to the severity of infection or abdominal adhesion. These factors result in more severe trauma after extended dissection and more local exudation, which in turn prolong postoperative recovery time and LOS. Therefore, although further large-scale studies will be needed in verifying our results, efforts are needed to reduce the operative time during laparoscopic appendectomy as much as possible.

CRP levels are commonly used as a nonspecific inflammatory marker in patients with an acute abdomen in several clinical settings [22]. Elevated CRP levels reflect the pathological severity of appendicitis and the degree of inflammation in an infection. Several studies have suggested that preoperative CRP levels were a potent predictor of postoperative SSI in patients undergoing appendectomy $[13,23]$, although the cutoff value of preoperative CRP level used as a predictor has been disputed [24]. The present study showed that preoperative CRP levels were an independent risk factor for delayed treatment completion in patients who underwent laparoscopic appendectomies for uncomplicated appendicitis. Based on our results, the most common cause of delayed treatment completion was SSI, accounting for 35 of 37 cases (94.6\%). In addition, preoperative CRP levels (OR, 1.367; 95\% CI, 
Table 4. Characteristics of patients in the uneventful and complicated groups

\begin{tabular}{|c|c|c|c|}
\hline Characteristic & Uneventful group & Complicated group & P-value \\
\hline No. of patients & 462 & 35 & \\
\hline Last follow-up after surgery (day) & $7.4 \pm 0.8(6-14)$ & $25.3 \pm 8.9(12-48)$ & $<0.001$ \\
\hline Age (yr) & $42.5 \pm 15.9$ & $39.4 \pm 12.0$ & 0.153 \\
\hline Sex & & & $>0.999$ \\
\hline Male & $236(51.1)$ & $18(51.4)$ & \\
\hline Female & $226(48.9)$ & $17(48.6)$ & \\
\hline Body mass index $\left(\mathrm{kg} / \mathrm{m}^{2}\right)$ & $23.5 \pm 3.8$ & $23.1 \pm 4.0$ & 0.538 \\
\hline Hypertension & & & $>0.999$ \\
\hline No & 403 (87.2) & $31(88.6)$ & \\
\hline Yes & $59(12.8)$ & $4(11.4)$ & \\
\hline Diabetes mellitus & & & 0.653 \\
\hline No & $443(95.9)$ & $33(94.3)$ & \\
\hline Yes & $19(3.8)$ & $2(5.7)$ & \\
\hline ASA PS classification & & & 0.644 \\
\hline I & $255(55.2)$ & $21(60.0)$ & \\
\hline$\|$ & $198(42.9)$ & $14(40.0)$ & \\
\hline$\geq I I I$ & $9(1.9)$ & $0(0.0)$ & \\
\hline Smoking history & & & 0.829 \\
\hline No & $367(79.4)$ & $27(77.1)$ & \\
\hline Yes & $95(20.6)$ & $8(22.9)$ & \\
\hline Previous surgical history & & & 0.573 \\
\hline No & 412 (89.2) & $30(85.7)$ & \\
\hline Yes & $50(10.8)$ & $5(14.3)$ & \\
\hline Preoperative body temperature $\left({ }^{\circ} \mathrm{C}\right)$ & $37.2 \pm 0.5$ & $37.4 \pm 0.6$ & 0.015 \\
\hline Preoperative WBC count $\left(\times 10^{9} / \mathrm{L}\right)$ & $11.8 \pm 4.0$ & $12.4 \pm 3.6$ & 0.395 \\
\hline Preoperative CRP level (mg/L) & $0.7 \pm 1.2$ & $1.9 \pm 3.0$ & $<0.001$ \\
\hline Maximal appendix diameter (mm) & $10.2 \pm 2.3$ & $12.3 \pm 3.3$ & 0.001 \\
\hline Appendicolith & & & 0.013 \\
\hline No & $333(72.1)$ & $18(51.4)$ & \\
\hline Yes & $129(27.9)$ & $17(48.6)$ & \\
\hline Time from admission to surgery (min) & $439.1 \pm 270.4$ & $480.0 \pm 301.7$ & 0.393 \\
\hline Surgeon & & & 0.347 \\
\hline A & $90(19.5)$ & $11(31.4)$ & \\
\hline B & $96(20.8)$ & $7(20.0)$ & \\
\hline C & $92(19.9)$ & $3(8.6)$ & \\
\hline $\mathrm{D}$ & $64(13.9)$ & $3(8.6)$ & \\
\hline $\mathrm{E}$ & $81(17.5)$ & $7(8.0)$ & \\
\hline $\mathrm{F}$ & $39(8.4)$ & $4(9.3)$ & \\
\hline Operative time (min) & $39.5 \pm 17.7$ & $45.0 \pm 18.3$ & 0.074 \\
\hline Surgeon $\mathrm{A}$ & $46.6 \pm 22.9$ & $46.5 \pm 20.3$ & 0.992 \\
\hline Surgeon B & $32.3 \pm 11.8$ & $30.3 \pm 13.3$ & 0.659 \\
\hline Surgeon C & $45.9 \pm 18.2$ & $48.3 \pm 10.4$ & 0.820 \\
\hline Surgeon D & $30.8 \pm 12.5$ & $39.0 \pm 10.5$ & 0.267 \\
\hline Surgeon $E$ & $40.1 \pm 16.0$ & $52.4 \pm 16.7$ & 0.054 \\
\hline Surgeon F & $38.2 \pm 12.2$ & $55.7 \pm 22.7$ & 0.015 \\
\hline
\end{tabular}

Values are presented as mean \pm standard deviation (range) or number (\%).

ASA, American Society of Anesthesiologists; PS, physical status; WBC, white blood cell; CRP, C-reactive protein. 
Table 5. Postoperative outcomes and factors associated with delayed treatment completion after laparoscopic appendectomy for uncomplicated appendicitis

\begin{tabular}{|c|c|c|c|}
\hline Characteristic & Uneventful group $(n=462)$ & Complicated group $(n=35)$ & P-value \\
\hline Clavien-Dindo classification & & & $<0.001$ \\
\hline 0 & $412(89.2)$ & $0(0)$ & \\
\hline$\|$ & $5(1.1)$ & $16(45.7)$ & \\
\hline Surgical site infection & & & $<0.001$ \\
\hline Superficial & $1(0.2)$ & $20(57.1)$ & \\
\hline Deep incisional & $0(0)$ & $12(34.3)$ & \\
\hline Organ/space & $0(0)$ & $3(8.6)$ & \\
\hline Readmission & & & $<0.001$ \\
\hline No & $462(100)$ & $30(85.7)$ & \\
\hline Wound seroma & & $9(24.3)$ & \\
\hline Intraabdominal abscess & & $3(8.1)$ & \\
\hline Postoperative ileus & & $2(5.4)$ & \\
\hline Wound cellulitis & & $1(2.7)$ & \\
\hline Skin dehiscence & & $1(2.7)$ & \\
\hline
\end{tabular}

Values are expressed as number (\%).

Table 6. Multivariate analysis of factors affecting delayed treatment completion after laparoscopic appendectomy for uncomplicated appendicitis

\begin{tabular}{lcr}
\hline Characteristic & OR $(95 \% \mathrm{Cl})$ & P-value \\
\hline Preoperative body temperature & $1.442(0.850-1.729)$ & 0.114 \\
Preoperative C-reactive protein & $1.384(1.121-1.568)$ & 0.007 \\
Maximal appendix diameter & $1.424(1.233-1.645)$ & $<0.001$ \\
Appendicolith & $1.330(0.619-2.860)$ & 0.465 \\
Operative time & $1.019(0.999-1.039)$ & 0.057 \\
\hline
\end{tabular}

$\mathrm{OR}$, odds ratio; $\mathrm{Cl}$, confidence interval.

1.109-1.500; $\mathrm{P}=0.009)$ were associated with a higher incidence of postoperative SSIs in multivariate analysis (Supplementary Table 1), which was statistically consistent with the risk factors for delayed treatment completion and SSI. Therefore, delayed treatment completion and SSI in patients with elevated preoperative CRP levels require careful attention.

We found that the maximal appendix diameter was significantly associated with delayed treatment completion after laparoscopic appendectomies in patients with uncomplicated appendicitis. As with preoperative CRP levels, the maximal diameter (OR, 1.390; 95\% CI, 1.210-1.597; $\mathrm{P}<0.001$ ) was an independent risk factor for postoperative SSI in this study (Supplementary Table 1). Han- sen et al. [25] reported that the appendix diameter based on abdominal CT was an important factor predicting the severity of appendicitis in a study comparing CT findings and final pathology. Liang et al. [26] suggested that appendix diameter might predict postoperative wound infections after a laparoscopic appendectomy, and when the diameter of the appendix was greater than $15 \mathrm{~mm}$, patients were 2.32-fold more likely to have a wound infection than those with an appendix of less than $10 \mathrm{~mm}$ in diameter. We thought that larger maximal appendix diameter increased the likelihood of perforation, and the possibility of microperforation, increasing the risk of SSI. Therefore, we suggest that the maximal appendix diameter is a valuable predictor of delayed treatment completion in relation to SSI after laparoscopic appendectomies in patients with uncomplicated appendicitis.

In the current study, SSI was not associated with risk factors for prolonged hospitalization, which was seen only in 2 of 39 cases (5.1\%) of prolonged LOS due to wound complications. This probably was because the typical timeframe for the appearance of SSI is 3 to 7 days after surgery, and patients who underwent laparoscopic appendectomies for uncomplicated appendicitis were usually discharged before that time. Therefore, a short-term followup might be required in selected patients discharged early after a laparoscopic appendectomy for uncomplicated appendicitis, especially those with elevated preoperative CRP levels and larger 
maximal appendix diameters.

This study had some limitations. First, the potential for selection bias was compounded by the retrospective design, which was the main limitation. Second, despite clear discharge criteria, they could be not applied to all patients because of the physician or patient preferences. However, the sample size was sufficient for the analysis, and our overall mean LOS was within the ranges previously reported. Third, gangrenous appendicitis without perforation or abscess was not distinguished, suggesting the need for caution in interpreting the results. Further well-designed prospective studies are needed to corroborate our results.

In conclusion, a shorter operative time is desirable to minimize hospital stay after laparoscopic appendectomies in patients with uncomplicated appendicitis. Additional efforts are needed to ensure that patients with uncomplicated appendicitis do not delay treatment completion after laparoscopic appendectomies, particularly those with elevated preoperative CRP levels and larger maximal appendix diameters.

\section{SUPPLEMENTARY MATERIALS}

Supplementary Table 1. Univariate and multivariate analysis of factors affecting surgical site infection after laparoscopic appendectomy

Supplementary material is available from https://doi.org/10.3393/ ac.2021.00773.0110.

\section{CONFLICT OF INTEREST}

No potential conflict of interest relevant to this article was reported.

\section{FUNDING}

None.

\section{REFERENCES}

1. Bhangu A, Søreide K, Di Saverio S, Assarsson JH, Drake FT. Acute appendicitis: modern understanding of pathogenesis, diagnosis, and management. Lancet 2015;386:1278-87.

2. Khalil M, Rhee P, Jokar TO, Kulvatunyou N, O'Keeffe T, Tang A, et al. Antibiotics for appendicitis! Not so fast. J Trauma Acute Care Surg 2016;80:923-32.

3. GlobalSurg Collaborative. Laparoscopy in management of appendicitis in high-, middle-, and low-income countries: a multicenter, prospective, cohort study. Surg Endosc 2018;32:3450-66.

4. Fernández-Moreno MC, Pérez Santiago L, Martí Fernández R, León Espinoza C, Ortega Serrano J. Is laparoscopic approach still a risk factor for postappendectomy intra-abdominal abscess? J Trauma Acute Care Surg 2021;90:163-9.

5. Varela JE, Wilson SE, Nguyen NT. Laparoscopic surgery signifi- cantly reduces surgical-site infections compared with open surgery. Surg Endosc 2010;24:270-6.

6. Quah GS, Eslick GD, Cox MR. Laparoscopic appendicectomy is superior to open surgery for complicated appendicitis. Surg Endosc 2019;33:2072-82.

7. de Wijkerslooth E, Bakas JM, van Rosmalen J, van den Boom AL, Wijnhoven B. Same-day discharge after appendectomy for acute appendicitis: a systematic review and meta-analysis. Int J Colorectal Dis 2021;36:1297-309.

8. Konstantinidis KM, Anastasakou KA, Vorias MN, Sambalis GH, Georgiou MK, Xiarchos AG. A decade of laparoscopic appendectomy: presentation of 1,026 patients with suspected appendicitis treated in a single surgical department. J Laparoendosc Adv Surg Tech A 2008;18:248-58.

9. Ming PC, Yan TY, Tat LH. Risk factors of postoperative infections in adults with complicated appendicitis. Surg Laparosc Endosc Percutan Tech 2009;19:244-8.

10. Parker MC, Ellis H, Moran BJ, Thompson JN, Wilson MS, Menzies D, et al. Postoperative adhesions: ten-year follow-up of 12,584 patients undergoing lower abdominal surgery. Dis Colon Rectum 2001;44:822-29.

11. Leung TT, Dixon E, Gill M, Mador BD, Moulton KM, Kaplan GG, et al. Bowel obstruction following appendectomy: what is the true incidence? Ann Surg 2009;250:51-3.

12. Zhang P, Zhang Q, Zhao H, Li Y. Factors affecting the length of hospital stay after laparoscopic appendectomy: a single center study. PLoS One 2020;15:e0243575.

13. Chen CL, Chao HC, Kong MS, Chen SY. Risk factors for prolonged hospitalization in pediatric appendicitis patients with medical treatment. Pediatr Neonatol 2017;58:223-8.

14. Walędziak M, Lasek A, Wysocki M, Su M, Bobowicz M, Myśliwiec $\mathrm{P}$, et al. Risk factors for serious morbidity, prolonged length of stay and hospital readmission after laparoscopic appendectomy: results from Pol-LA (Polish Laparoscopic Appendectomy) multicenter large cohort study. Sci Rep 2019;9:14793.

15. Kim WJ, Jin HY, Lee H, Bae JH, Koh W, Mun JY, et al. Comparing the postoperative outcomes of single-incision laparoscopic appendectomy and three port appendectomy with enhanced recovery after surgery protocol for acute appendicitis: a propensity score matching analysis. Ann Coloproctol 2021;37:232-8.

16. Clavien PA, Barkun J, de Oliveira ML, Vauthey JN, Dindo D, Schulick RD, et al. The Clavien-Dindo classification of surgical complications: five-year experience. Ann Surg 2009;250:187-96.

17. Horan TC, Gaynes RP, Martone WJ, Jarvis WR, Emori TG. CDC definitions of nosocomial surgical site infections, 1992: a modification of CDC definitions of surgical wound infections. Am J Infect Control 1992;20:271-4.

18. Kim TH, Cho BS, Jung JH, Lee MS, Jang JH, Kim CN. Predictive factors to distinguish between patients with noncomplicated appendicitis and those with complicated appendicitis. Ann Coloproctol 2015;31:192-7.

19. Salminen P, Paajanen H, Rautio T, Nordström P, Aarnio M, Ran- 


\section{Coloproctology Jiyoung Shin, et al.}

tanen T, et al. Antibiotic therapy vs appendectomy for treatment of uncomplicated acute appendicitis: the APPAC Randomized Clinical Trial. JAMA 2015;313:2340-8.

20. Grigorian A, Kuza CM, Schubl SD, Nguyen NT, de Virgilio C, Kim D, et al. Same-day discharge after non-perforated laparoscopic appendectomy is safe. J Invest Surg 2021;34:270-5.

21. Schlottmann F, Sadava EE, Peña ME, Rotholtz NA. Laparoscopic appendectomy: risk factors for postoperative intraabdominal abscess. World J Surg 2017;41:1254-8.

22. Asfar S, Safar H, Khoursheed M, Dashti H, al-Bader A. Would measurement of $\mathrm{C}$-reactive protein reduce the rate of negative exploration for acute appendicitis? J R Coll Surg Edinb 2000;45:214.

23. Shimizu T, Ishizuka M, Kubota K. The preoperative serum C-re- active protein level is a useful predictor of surgical site infections in patients undergoing appendectomy. Surg Today 2015;45:140410.

24. Yu CW, Juan LI, Wu MH, Shen CJ, Wu JY, Lee CC. Systematic review and meta-analysis of the diagnostic accuracy of procalcitonin, C-reactive protein and white blood cell count for suspected acute appendicitis. Br J Surg 2013;100:322-9.

25. Hansen AJ, Young SW, De Petris G, Tessier DJ, Hernandez JL, Johnson DJ. Histologic severity of appendicitis can be predicted by computed tomography. Arch Surg 2004;139:1304-8.

26. Liang HH, Wang W, Huang MT, Hung CS, Yen KL, Lee WJ, et al. Appendix diameter: a predictor of wound infection after laparoscopic appendectomy. Am Surg 2011;77:307-10. 